\title{
LÓC NGƯỢC ĐộNG MẠCH CHỦ TYPE A SAU CAN THIỆP NộI MẠCH ĐộNG MẠCH CHƯ NGỰC: KẾT QUẢ TẠI BỆNH VIỆN HỮU NGHİ VIỆT ĐỨC
}

TÓM TẮT.

Đặt vấn đề: Lóc ngược động mach chủ type $A$ sau can thiệp nội mạch động mạch chủ ngực là một biến chứng hiếm gặp nhưng đe dọa tính mạng bệnh nhân. Chúng tôi hồi cứu các trường hợp lâm sàng lóc ngược động mạch chủ type A tại Trung tâm tim mạch và lồng ngực - Bênh viên Hữu nghi Việt Đức và nhìn lại y văn. Đối tượng và phương pháp nghiên cứu: Mô tả hồi cứu các bênh nhân lóc ngước động mach chủ type $A$ sau can thiệp nội mạch động mạch chủ ngưc giai đoạn từ 2017 - 2021. Kết quả: Có 7 bệnh nhẩn trong nghiên cứu, độ tuổi trung bình $56.9 \pm 13.9$ tuổi (31-70), nam/ nữ: $5 / 2$. Bênh căn trước can thiêp nội mạch bao gồm: 5(71.4\%) - lóc động mạch chủ type $B$, trong đó cấp tính: $4(57.1 \%) ; 2(28.6 \%)$ bênh nhân có phồng quai động mạch chủ và động mạch chủ xuống. 2 (28.6\%) bênh nhân có đường kính đồng mach chủ lên $>4 \mathrm{~cm}$. Kiểu hình Marfan gặp ở 14.3\%. Đầu gân ống ghép nội mạch đătt vào vùng từ 0 đến 2 , trong đó vùng 0 chiếm $14.3 \%$, vùng I và II có tỉ lế bằng nhau và bằng $42.9 \%$; Đường kính ống ghép nội mạch lớn hơn động mạch chủ từ 9 đến $9.7 \%$. Có 4 bệnh nhân kịp phẫu thuật, cả 4 bệnh nhân được thay quai đông mach chủ và động mạch chủ lên. 2 bênh nhân tử vong khi chưa kịp mở ngực, 1 bệnh nhân tử vong tuyến dưới. Có 01 bênh nhân tử vong sau mổ, tỉ lệ ra viện $42.9 \%$, tỉ lệ tử vong sau mổ $25 \%$, tỉ lệ tử vong chung là $57.1 \%$. Kết luận: Lóc ngược động mạch chủ type $A$ sau can thiệp nội mạch là một biến chứng nặng nề, diễn biến nhanh, nặng và nguy cơ tử vong cao kể cả được phẫu thuật kịp thời. Đánh giá các yếu tố nguy cơ trước can thiệp và lựa chọn phương án điều trị phù hợp giúp giảm tỉ lệ biến chứng này.

Tư khóa: Lóc ngược động mạch chủ type A, can thiệp nội mạch động mạch chủ.

\section{SUMMARY}

RETROGRADE TYPE A AORTIC DISSECTION AFTER ENDOVASCULAR THORACIC AORTIC REPAIR: RESULTS AT VIET DUC UNIVERSITY HOSPITAL

Background: Retrograde type A aortic dissection after thoracic aortic endovascular repair is a rare but lethal complication. We retrospectively analysis clinical cases with retrograde type $A$ aortic dissection after thoracic aortic endovascular repair at Cardiovascular and Thoracic Center - Viet Duc Hospital and reviewed

\footnotetext{
${ }^{1}$ Bệnh viện Hữu Nghị Việt Đức

¿Đại họ Y Hà Nội

Chịu trách nhiệm chính: Phùng Duy Hồng Sơn

Email: hongsony81@yahoo.com

Ngày nhận bài: 25.10.2021

Ngày phản biện khoa học: 20.12.2021

Ngày duyệt bài: 27.12.2021
}

\section{Phùng Duy Hồng Sơn ${ }^{1,2}$, Lê Hồng Quân ${ }^{1}$}

the literature. Patient and methods: This is retrospective, descriptive study of patients, who had retrograde type $A$ aortic dissection after thoracic aortic endovascular repair from 2017 to 2021. Results: There were 7 patients in this study, the average age was $56.9 \pm 13.9$ years (31-70). The male/female ratio was 5/2. Reasons for first intervention were: type $B$ aortic dissection in fine $(71.4 \%)$, of which acute dissection was in four $(57.1 \%)$; aneurysm of descending aorta and aortic arch in two (28.6\%). Two $(28.6 \%)$ patients had ascending aorta diameter > $4 \mathrm{~cm}$. Marfan syndrome was presented in one (14.3\%). The proximal landing zone from zone 0 to zone 2, in which the zone 0 accounts for $14.3 \%$, the zone I and II have the same ratio and equal to $42.9 \%$. The stent graft oversizing was from 9 to $9.7 \%$. Four patients underwent total aortic arch and ascending aorta replacement and two patients were died on operating table before surgery, one patient died at province hospital, one patient died after surgery, the survival rate was $42.9 \%$, postoperative mortality rate was $25 \%$, the total mortality rate was $57.1 \%$. Conclusion: Retrograde type A aortic dissection after endovascular intervention is a serious complication, rapid progression with high mortality even with timely surgery. Assess risk factors before intervention and select appropriate treatment options to help reduce this complication rate.

Keywords: Retrograde type A aortic dissection, aortic endovascular repair.

\section{I. ĐĂT VẤN ĐỀ}

Can thiệp nội mạch động mạch chủ (ĐMC) là một phương pháp ít xâm lấn được sử dụng ngày càng nhiều để điều trị các bệnh lý ĐMC ngực ${ }^{1,2}$ như phồng $Đ M C$ ngực, lóc $Đ M C$ type $B$, loét xuyên thành $Đ M C$, hay một số bệnh lý $Đ M C$ khác ${ }^{3}$. Tuy nhiên, phương pháp này cũng có các biến chứng nghiêm trọng, chẳng hạn như đột quy, rò và lóc ngược động mạch chủ type $A^{3-5}$, trong đó là tai biến lóc ngược ĐMC type $A$ - là một tai biến rất nặng $2,3,6$. Theo một vài nghiên cứu thì lóc ngược ĐMC type $A$ sau can thiệp nội mạch ĐMC ngực hiếm khoảng $1.33-2.5 \% 2,4,7,8$, trong đó tỉ lệ tử vong lại rất cao đến 37.1 $42 \%{ }^{2,4}$. Mặc dù nguyên nhân của lóc ngược ĐMC type $\mathrm{A}$ sau can thiệp nội mạch $Đ M C$ ngực vẫn chưa được hiểu đầy đủ nhưng một số yếu tố nguy cơ tiên lượng đã được báo cáo như về mặt chỉ định, trang thiết bị, yếu tố kỹ thuật tại thời điểm thực hiện can thiệp nội mạch $Đ M C$ ngực ${ }^{7}$. Kết quả cho thấy phẫu thuật thay toàn bộ quai ĐMC vẫn là một lựa cho tổi ưu để điều trị lóc ngược động mạch chủ type $A$ sau can thiệp nội 
mạch ĐMC ngực ${ }^{5}$. Chúng tôi báo cáo các trường hợp lâm sàng có lóc ngược ĐMC type A tại Trung tâm Tim mạch và Lông ngực - Bệnh viện Hữu nghị Việt Đức, xử trí và nhìn lại y vắn.

\section{KẾT QUẢ NGHIÊN CỨU}

Có 7 bệnh nhân trong nghiên cứu, các đặc điểm lâm sàng, cậm lâm sàng trình bày bảng 1.

Bảng 1: Đặc điểm lâm sàng, cận lâm sàng $(N=7)$

\begin{tabular}{|c|c|c|c|c|}
\hline \multicolumn{3}{|c|}{ Đạcc điểm } & Số bênh nhân & $\%$ \\
\hline \multicolumn{3}{|c|}{ Tuổi trung bình (năm) } & $56.9 \pm 13.9(31-70)$ & \\
\hline \multirow{2}{*}{ Giới tính } & \multicolumn{2}{|r|}{ Nam } & 5 & 71,4 \\
\hline & \multicolumn{2}{|r|}{ Nũ } & 2 & 29,6 \\
\hline \multirow{4}{*}{$\begin{array}{l}\text { Bệnh kèm } \\
\text { theo }\end{array}$} & \multicolumn{2}{|r|}{ Cao huyết áp } & 6 & 85,7 \\
\hline & \multicolumn{2}{|r|}{ Đái tháo đường } & 1 & 14,3 \\
\hline & \multicolumn{2}{|r|}{ Hội chứng Marfan } & 1 & 14,3 \\
\hline & \multicolumn{2}{|c|}{ Đường kính động mạch chủ lên > 4cm } & 2 & 28,6 \\
\hline \multirow{3}{*}{$\begin{array}{l}\text { Bệnh trước } \\
\text { can thiệp }\end{array}$} & \multirow{2}{*}{ Lóc ĐMC type B } & Cấp tính & 4 & 57,1 \\
\hline & & Mạn tính & 1 & 14,3 \\
\hline & \multicolumn{2}{|c|}{ Phông quai ĐMC và ĐMC xuống } & 2 & 28,6 \\
\hline \multirow{4}{*}{$\begin{array}{c}\text { Điêu trị lân } \\
1\end{array}$} & \multirow{3}{*}{ Hybrid } & $\begin{array}{l}\text { Bắc câu ĐM cảnh- cảnh, ĐM cảnh- } \\
\text { ĐM dưới đòn + ống ghép nội mạch }\end{array}$ & 3 & 42.9 \\
\hline & & $\begin{array}{l}\text { Bắc câu ĐMC- ĐM cảnh hai bên + } \\
\text { ống ghép nội mạch }\end{array}$ & 1 & 14,3 \\
\hline & & $\begin{array}{l}\text { Bắc câu ĐM cảnh - ĐM dưới đòn } \\
\text { trái + ống ghép nội mạch }\end{array}$ & 1 & 14,3 \\
\hline & Can thiệp đơn thuân & ống ghép nội mạch ĐMC & 2 & 28,6 \\
\hline \multirow{2}{*}{$\begin{array}{l}\text { Triệu chứng } \\
\text { ló́c ĐMC }\end{array}$} & \multicolumn{2}{|r|}{ Đau ngực } & 7 & 100 \\
\hline & \multicolumn{2}{|r|}{ Chèn ép tim cấp } & 6 & 85,7 \\
\hline
\end{tabular}

Đầu gân ống ghép nội mạch ĐMC đặt vào vùng từ 0 đến 2 , trong đó vùng 0 chiếm $14.3 \%$, vùng I và II có tỉ lệ bằng nhau và bằng 42.9\%; kích thước ống ghép nội mạch lớn hơn ĐMC từ 9 đến $9.7 \%$. Thời gian phát hiện lóc ngược ĐMC type $A$ sau can thiệp nội mạch ĐMC lúc khởi phát bệnh đến khi

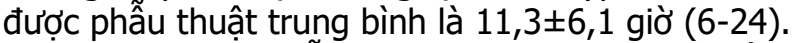

Phương pháp phẫu thuật và kết quả được thể hiện trong bảng 2.

\section{Bảng 2: Phẩu thuật và kêt quả}

\begin{tabular}{|c|c|c|c|c|}
\hline Bệnh & Can thiệp lân & \multicolumn{2}{|c|}{ Xử lý lóc ngược ĐMC type A } & Kết quả \\
\hline 1 & & $\begin{array}{c}\text { Dẫn lưu màng tim } \\
\text { cấp cứu } \\
\text { Thiết lập THNCT } \\
\text { qua ĐM và TM đùi }\end{array}$ & Chưa kịp phẫu thuật & $\begin{array}{l}\text { Tử vong trong khi đang } \\
\text { thiết lập THNCT ngoại } \\
\text { vi, trước khi mở xương } \\
\text { ức }\end{array}$ \\
\hline 2 & & $\begin{array}{c}\text { Thay ĐMC lên và } \\
\text { quai ĐMC } \\
\text { Thiết lập THNCT } \\
\text { qua ĐM và TM đùi }\end{array}$ & $\frac{013}{64}$ & $\begin{array}{c}\text { Tử vong sau mổ } 2 \text { tuần } \\
\text { do nhiễm khuẩn }\end{array}$ \\
\hline 3 & 2000 & $\begin{array}{l}\text { Thiết lập THNCT } \\
\text { qua ĐM và TM đùi }\end{array}$ & Chưa kịp phẫu thuật & $\begin{array}{c}\text { Tử vong trong khi đang } \\
\text { thiết lập THNCT ngoại } \\
\text { vi, trước khi mở xương } \\
\text { ức }\end{array}$ \\
\hline
\end{tabular}




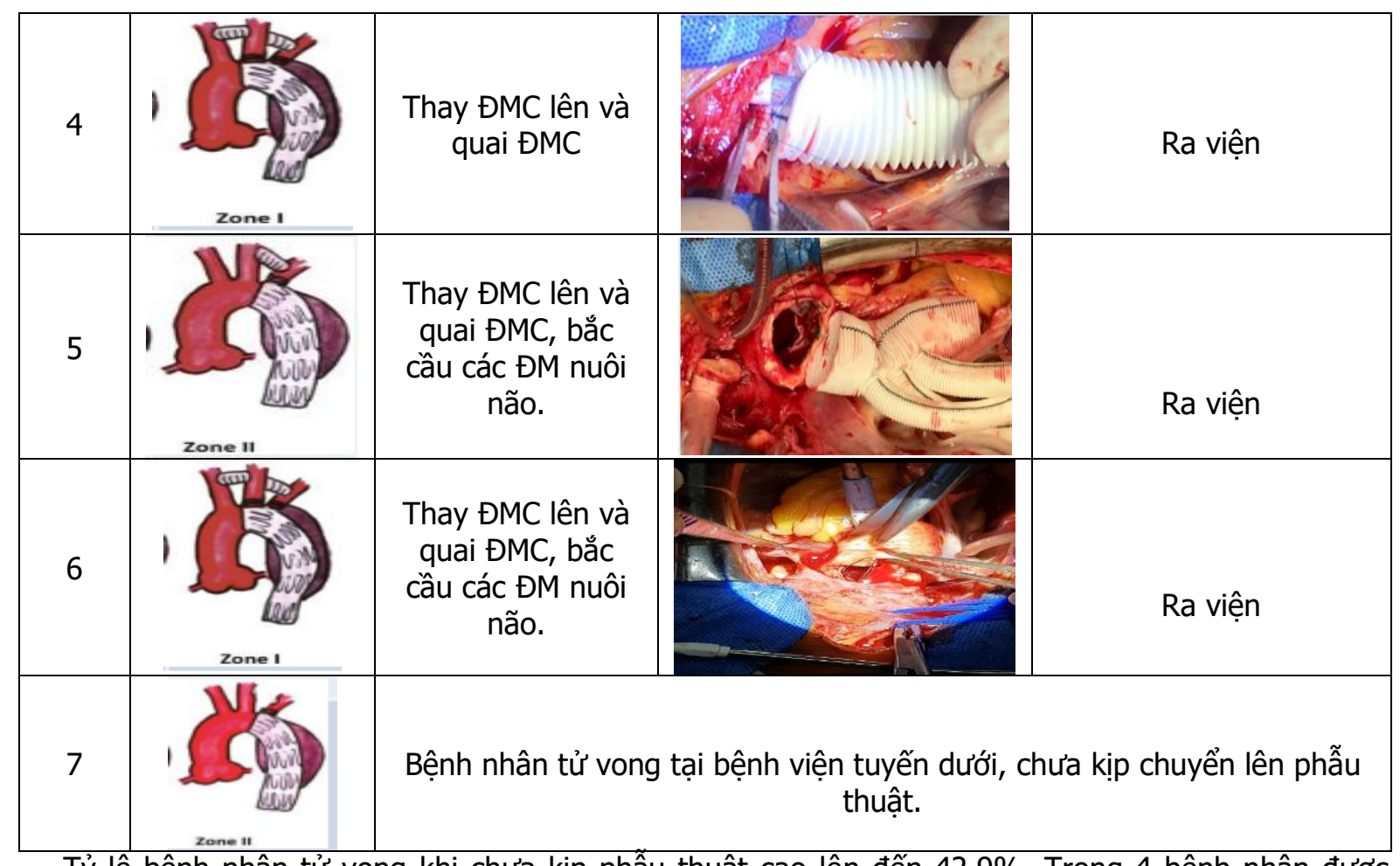

Tỷ lệ bệnh nhân tử vong khi chưa kịp phẫu thuật cao lên đến 42.9\%. Trong 4 bệnh nhân được phẫu thuật, có 01 bệnh nhân tử vong sau mổ, tỉ lệ ra viện $42.9 \%$, tỉ lệ tử vong sau mổ $25 \%$, tỉ lệ tử vong chung là $57.1 \%$.

\section{BÀN LUẬN}

Can thiệp nội mạch ĐMC ngực là một phương pháp hiện đại được sử dụng để điều trị các bệnh lý ĐMC ngực giúp đơn giản hóa quá trình điều trị với xâm lấn tối thiểu ${ }^{1-3}$. Tuy nhiên phương pháp này cũng có những biến chứng nặng nề, một trong số đó là tai biến lóc ngược ĐMC type $A^{2,3,6}$. Theo một vài nghiên cứu thì tỉ lệ lóc ngược $Đ M C$ type $A$ sau can thiệp nội mạch ĐMC ngực hiếm gặp, chiếm khoảng $1.33-2.5 \% \%^{2,4,7,8}$, trong đó tỉ lệ tử vong rất cao đến $37.1-42 \% \%^{2,4}$. Kết quả nghiên cứu của chúng tôi thấy tỉ lệ tử vong chung $57.1 \%$ trong đó $42.9 \%$ tử vong trước khi mở xương ức, ti lệ tử vong sau mổ $25 \%$. Biến chứng này có thể xuất hiện sau can thiệp nội mạch ngay lập tức hoặc trong tháng đầu cũng có thể nhiêu tháng, nhiều năm sau đó, tuy nhiên một số báo cáo cho thây $40-46 \%$ xảy ra trong vòng 30 ngày, $80 \%$ trong vòng 1 năm và sau 1 năm là $2.5-10 \% 4,8$.

Mặc dù nguyên nhân của lóc ngược động mạch chủ type $A$ sau can thiệp nội mạch ĐMC ngực vẫn chưa được hiểu đầy đủ nhưng một số yếu tố nguy cơ tiên lượng đã được báo cáo?:

$\checkmark$ Đầu tiên, liên quan đến các chỉ định cho can thiệp nội mạch ĐMC ngực: (1) Lóc ngược ĐMC xuống có nhiều khả năng phát triển thành lóc ngược ĐMC type $A$ hơn bệnh lý phình ĐMC hay là chấn thương $\mathrm{DMC}$ và lóc động mạch chủ cấp tính là có nhiều khả năng hơn là mãn tính ${ }^{2,4}$, (2) Bệnh nhân có bệnh lý mô liên kết như hội chứng Marfan (8.3\%), hội chứng Ehler-Danlos và bệnh thận đa nang ${ }^{4}$, (3) Bệnh nhân có van ĐMC hai lá van và ĐMC lên $\geq 4 \mathrm{~cm}$, (4) Bệnh nhân lóc ĐMC type $B$ có huyết khối lòng giả, đặc biệt là những bệnh nhân có huyết khối lòng giả một phần thì tỉ lệ tử vong tăng 2.7 lần so với toàn phần, rò sau can thiệp cũng làm tăng sự tiến triển lòng giả dẫn đến nguy cơ lóc ngược $Đ M C$ type $A$, (5) Mất vị trí liên kết xoang- ống nối, hoặc dị dạng quai ĐMC. Nghiên cứu của chúng tôi thấy bệnh căn trước can thiệp bao gồm lóc ĐMC type $B$ chiếm $71.4 \%$ trong đó cấp tính: $57.1 \%$, mạn tính: $14.3 \%$; phồng quai ĐMC và ĐMC chiếm $28.6 \%$, đường kính động mạch chủ lên $>4 \mathrm{~cm}$ chiếm $28.6 \%$, kiểu hình Marfan gặp ở $14.3 \%$.

$\checkmark$ Về cấu tạo ống ghép nội mạch có nhiều tài liệu cho thấy nguy cơ lóc ngược động mạch chủ type $\mathrm{A}$ cao hơn ở những bệnh nhân được điều trị bằng loại ống ghép nội mạch có "bare stent" ở đầu gần 2,6 tuy nhiên một số báo cáo hệ thống gần đây về dữ liệu từ 4750 bệnh nhân được điêu trị bằng can thiệp nội mạch ĐMC ngực đã 
quan sát thấy rằng không có sự khác biệt về tỷ lệ lóc ngược ĐMC $A$ ở những bệnh nhân được điều trị bằng ống ghép nội mạch có "bare stent" hoặc không có "bare stent" ${ }^{\prime 2,4}$. Ngoài ra kích thước của ống ghép nội mạch cũng rất quan trọng, thông thường đường kính ống ghép nội mạch lớn hơn ĐMC trung bình là khoảng 10-15\% là đủ để đạt được sự ổn định mà không làm tổn thương lớp nội mạc ĐMC, ở những bệnh nhân sử dụng kích thước ống ghép nội mạch lớn hơn $20 \%$ so với đường kính ĐMC cũ̃ng là một yếu tố nguy cơ của lóc ngước đông mach chủ type A sau can thiêp ${ }^{2,3}$. Tất cả bệnh nhận trong nghiên cứu của chúng tôi đều dùng ống ghép nội mạch có "bare stent" và đường kính của ống ghép nội mạch lớn hơn ĐMC trong khoảng từ 9-9.7\% (Bảng 1).

$\checkmark$ Về vấn đề yếu tố kỹ thuật thì một số nghiên cứu cho thấy rằng việc đặt ống ghép nội mạch vào vị trí quai ĐMC (vùng 0 -2) là một yểu tố nguy cơ đáng kể của lóc ngược động mạch chủ type $A^{2,4}$, tî lệ cao hơn ở vùng 0 lên đến $6.8 \%$ trong khi đó ở vùng 3,4 là $1.3 \%$. Nguyên nhân có thể được giải thích do ống ghép nội mạch là vật liệu cứng, khi đặt vào vùng quai ĐMC sẽ bị cong, mà ống ghép nội mạch giống như lò xo nên luôn có xu hướng quay trở lại tư thế thẳng nếu bị cong thụ động, do vậy nó càng tác động mạnh vào lớp nội mạc ĐMC gây thương tổn 2,3; việc sử dụng bóng để nong ống ghép nội mạch ĐMC cũng được coi là một yếu tố nguy cớ ${ }^{4}$. Ngoài ra, tăng huyết áp không kiểm soát được sau can thiệp nội mạch ĐMC ngực có ảnh hưởng bất lợi đển thành động mạch chủ cũng làm tăng tỉ lệ lóc ngược động mạch chủ type $A^{5}$. Trong nghiên cứu này thì đầu gẩn ống ghép nội mạch động mạch chủ đặt vào vùng từ 0 đến 2 , trong đó vùng 0 chiếm $14.3 \%$, vùng I và II có tî lệ bằng nhau và bằng $42.9 \%$.

Theo Yaojun Dun và cộng sự thì có 4 điểm quan trọng cân được xem xét khi phẫu thuật lóc ngược ĐMC type $A$ sau can thiệp nội mạch. Đầu tiên phải loại bỏ hoàn toàn vị trí động mạch chủ bị tổn thương rách (thường hay gặp tại vị trí "bare stent") để ngăn chặn sự tiến triển của nó. Thứ hai, cắt bỏ "bare stent", nếu không "bare stent" có thể làm rách các đường khâu và dẫn đến rò rỉ, chảy máu hoặc tổn thương động mạch chủ thêm sau này. Thứ ba, tác giả sử dụng kỹ thuật vòi voi cải tiến có sử dụng ống ghép nội mạch để tái tạo đoạn quai sẽ ổn định, thuận tiện và hiệu quả cầm máu tốt hơn và chống di lệch của ổng ghép nội mạch cũ. Cuối cùng là các chiến lược bảo vệ não, đặc biệt là tưới máu não chọn lọc nên được áp dụng vì thời gian ngừng tuần hoàn hạ thân nhiệt thường dài hơn so với phẫu thuật quai ĐMC thông thường. Kết quả cho thấy phẫu thuật thay toàn bộ quai ĐMC có hoặc không kèm theo kỹ thuât "vòi voi cải tiến" vẫn là một lựa cho tối ưu để điều trị lóc ngược động mạch chủ type A sau can thiệp nội mạch ĐMC ngực.

\section{KẾT LUÂN}

Lóc ngược động mạch chủ type $A$ là một biến chứng hiếm gặp sau can thiệp nội mạch động mạch chủ ngực nhưng diễn biến nhanh và nguy cơ tử vong cao kể cả được phẫu thuật kịp thời. Để giảm tỉ lệ biến chứng nguy hiểm này cần phát hiện các yếu tố nguy cơ trước can thiệp để chọn phương pháp điều trị phù hợp.

\section{TÀI LIÊU THAM KHẢO}

1. Fattori $R$, Nienaber CA, Rousseau $H$, et al. Results of endovascular repair of the thoracic aorta with the Talent Thoracic stent graft: The Talent Thoracic Retrospective Registry. The Journal of Thoracic and Cardiovascular Surgery. 2006;132(2):332-339.

doi:10.1016/j.jtcvs.2006.03.055

2. Chen $Y$, Zhang S, Liu L, Lu Q, Zhang $T$, Jing $Z$. Retrograde Type A Aortic Dissection After Thoracic Endovascular Aortic Repair: A Systematic Review and Meta-Analysis. Journal of the American Heart Association. doi:10.1161/JAHA.116.004649

3. Kpodonu J, Preventza O, Ramaiah VG, et al. Retrograde type A dissection after endovascular stenting of the descending thoracic aorta. Is the risk real? European Journal of Cardio-Thoracic Surgery. doi:10.1016/j.ejcts.2008.03.024

4. Eggebrecht $H$, Thompson $M$, Rousseau $H$, et al. Retrograde Ascending Aortic Dissection During or After Thoracic Aortic Stent Graft Placement. Circulation. 2009;120(11_suppl_1):S276-S281. doi:10.1161/CIRCULATIONAHA.108.835926

5. Dun $Y$, Shi $Y$, Guo $H$, et al. The surgical management of retrograde type A aortic dissection after thoracic endovascular aortic repair. Interactive CardioVascular and Thoracic Surgery. 2020;30(5):732-738. doi:10.1093/icvts/ivz326

6. Neuhauser B, Greiner A, Jaschke $W$, Chemelli A, Fraedrich G. Serious complications following endovascular thoracic aortic stent-graft repair for type $\mathrm{B}$ dissection. European Journal of Cardio-

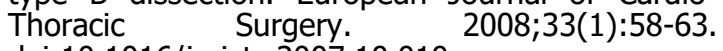
doi:10.1016/j.ejcts.2007.10.010

7. Hayakawa M, Nagano T, Nishijima I, et al. Retrograde Type A Aortic Dissection after Thoracic Endovascular Aortic Repair for Type B Dissection. The Heart Surgery Forum. 2020;23:E524-E526. doi:10.1532/hsf.3009

8. Wang $L$, Zhao $\mathbf{Y}$, Zhang $\mathbf{W}$, et al. Retrograde Type A Aortic Dissection after Thoracic Endovascular Aortic Repair: Incidence, Time Trends and Risk Factors. Seminars in Thoracic and Cardiovascular Surgery. 2021;33(3):639-653. doi:10.1053/j.semtcvs.2020.11.010. 